\title{
SUPRACONDYLAR OSTEOTOMY OF THE HUMERUS FOR CORRECTION OF CUBITUS VARUS
}

\author{
M. C. Bellemore, I. R. BARRETT, R. W. D. MIDDLETON, J. S. SCOUGALL, D. W. WHITEWAY
}

\author{
From the Royal Alexandra Hospital for Children, Sydney
}

\begin{abstract}
Cubitus varus is the most common complication of supracondylar fracture of the humerus in children. Although function of the elbow is not greatly impaired, the deformity is unsightly. It usually results from malunion, since growth disturbance of the humerus after this fracture is uncommon. The normal carrying angle can be restored by supracondylar osteotomy. This operation was done in 32 patients over a ten-year period, 16 of them using the technique described by French (1959). The results in 27 patients are reviewed in the light of previous reports. French's method proved safe and satisfactory.
\end{abstract}

Supracondylar fracture of the humerus is the most common elbow injury in childhood (Siris 1939; Mitchell and Adams 1961; Griffin 1975). Nerve damage or vascular insufficiency may be associated with the injury or with reduction. However, cubitus varus (gunstock deformity) is the most common long-term complication (Mitchell and Adams 1961; Amspacher and Messenbaugh 1964; Langenskiöld and Kivilaakso 1967). The deformity is unsightly and although function is not greatly impaired, the child's parents often request an operation to improve the appearance of the elbow (French 1959).

Many published papers are concerned with the early management of supracondylar fracture, but few deal with the management of cubitus varus. Several methods of corrective osteotomy at the distal humerus have been described (Table I). Only five authors report more than four cases, and in all of the series there was a high complication rate. French, in 1959, reported a procedure which "gives a good exposure, robs the operation of some of its dangers, provides a method for satisfactory control of the osteotomy and allows for earlier mobilisation of the elbow". There are no published reports of the results of his operation.

This present paper reviews the published work on cubitus varus deformity and reports the results of corrective osteotomy during a 10-year period at the Royal Alexandra Hospital for Children, Sydney.

M. C. Bellemore, MB BS, Orthopaedic Registrar

I. R. Barrett, FRACS, Orthopaedic Surgeon

R. W. D. Middleton, FRCS, FRACS, Orthopaedic Surgeon

J. S. Scougall, FRCS, FRACS, Orthopaedic Surgeon

D. W. Whiteway, FRCS, FRACS, FACS, Orthopaedic Surgeon

Department of Orthopaedic Surgery, Royal Alexandra Hospital for

Children, Pyrmont Bridge Road, Camperdown, NSW, Australia.

Requests for reprints should be sent to Dr I. R. Barrett.

(C) 1984 British Editorial Society of Bone and Joint Surgery $0301-620 X / 84 / 4137 \$ 2.00$

\section{MATERIAL AND METHODS}

Supracondylar osteotomy for the correction of cubitus varus was carried out in 32 children between July 1973 and July 1983. There were 21 boys and 11 girls, all of whom had malunion after an extension type of supracondylar fracture of the humerus. The mean age at injury was six years, and at osteotomy nine years. The right and left elbows were equally involved.

Mechanism of injury. All fractures were caused by falls, usually on the outstretched arm, although in many of the younger children the exact mechanism was uncertain. The most common single cause was a fall from a bicycle. Initial treatment. In all but one case the initial treatment was by closed reduction under general anaesthesia; reduction was held by a collar and cuff, sometimes supplemented by a posterior plaster splint. The initial treatment in one child was by open reduction and internal fixation with Kirschner wires. This was done at another hospital, as were the closed reductions for 28 of the patients; all were subsequently referred to us for the late management of the deformity. Only three children were treated initially by closed reduction at our hospital. Two children had both closed reduction and a supracondylar osteotomy elsewhere before referral for management of persisting cubitus varus.

Indications. The main indication for operation in all cases was that the appearance of the elbow was unacceptable to the child's parents. Two children also had specific disabilities; one had difficulty in swimming and the other could not achieve a desired grade in judo.

Osteotomy. All operations were performed by or under the supervision of one of the authors. In all cases a wedge was excised and the gap closed. Three methods of holding position were used: in three children external plaster of Paris alone, in $13 \mathrm{Kirschner}$ wires, and in 16 a technique modified from French (1959). 
Table I. Papers reporting cases having osteotomy for cubitus varus following supracondylar fracture

\begin{tabular}{|c|c|c|c|c|c|}
\hline Author & Date & Number of cases & Type of osteotomy & Method of bolding & Reported results \\
\hline Siris & 1939 & 2 & Lateral closing wedge & Lane plate & Failure of fixation in 1 \\
\hline King and Secor & 1951 & 15 & $\begin{array}{l}\text { Medial opening wedge } \\
\text { tibial bone graft }\end{array}$ & $\begin{array}{l}2 \text { Steinmann pins } \\
\text { Riedel clamp }\end{array}$ & $\begin{array}{l}12 \text { "perfect corrections" } \\
3 \text { straight arms }\end{array}$ \\
\hline French & 1959 & - & $\begin{array}{l}\text { Lateral closing wedge and } \\
\text { rotation }\end{array}$ & 2 screws and wire loop & - \\
\hline Smith & 1960 & 1 & Osteotomy & Overhead skeletal traction & Normal carrying angle \\
\hline $\begin{array}{l}\text { Amspacher and } \\
\text { Messenbaugh }\end{array}$ & 1964 & 4 & Oblique osteotomy & 1 screw & "Well corrected in each case" \\
\hline $\begin{array}{l}\text { Langenskiöld and } \\
\text { Kivilaakso }\end{array}$ & 1967 & 11 & $\begin{array}{l}\text { Lateral closing wedge } \\
\text { (occasionally with lateral } \\
\text { rotation) }\end{array}$ & Plate & 5 with normal carrying angle \\
\hline Nassar & 1974 & 4 & $\begin{array}{l}\text { Lateral closing wedge and } \\
\text { rotation }\end{array}$ & 2 crossed Kirschner wires & "Excellent" \\
\hline Rang & 1974 & 8 & Lateral closing wedge & $\begin{array}{l}\text { In cast with pronated forearm } \\
\text { and flexed elbow }\end{array}$ & Position lost in 3 \\
\hline Rang & 1974 & 20 & Lateral closing wedge & Kirschner wires & $\begin{array}{l}17 \text { satisfactory, some serious } \\
\text { complications }\end{array}$ \\
\hline Sweeney & 1975 & 14 & Lateral closing wedge & 2 crossed Kirschner wires & $\begin{array}{l}\text { "In } 5 \text { patients varus } \\
\text { deformity not eradicated" }\end{array}$ \\
\hline Griffin & 1975 & - & $\begin{array}{l}\text { Lateral closing wedge } \\
\text { medial hinge }\end{array}$ & $\begin{array}{l}\text { In cast with pronated forearm } \\
\text { and flexed elbow }\end{array}$ & - \\
\hline
\end{tabular}

In the modified French technique the lower humerus is exposed by making a posterolateral incision, and splitting the triceps. The lateral third of the triceps is then detached from its insertion and reflected proximally, and the medial two-thirds of the muscle is lifted from the humerus subperiosteally, thus protecting the ulnar nerve. An appropriate laterally-based wedge is then marked on the bone, ending just short of the medial cortex. One screw is placed into the lateral cortex above and another
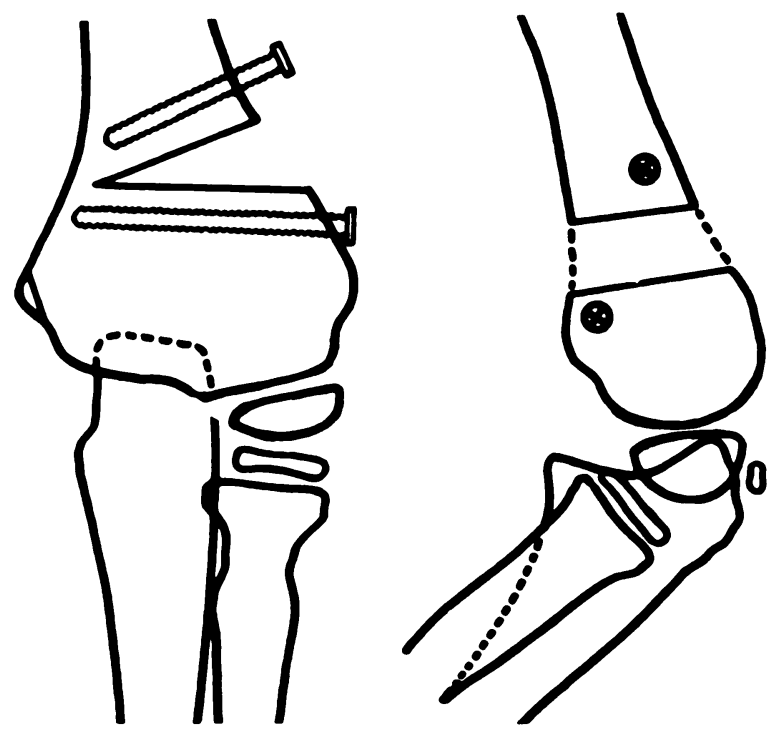

Fig. 1

A French osteotomy before the wedge is closed and wire applied (French 1959). See also Fig. 12. below the proposed osteotomy (Fig. 1). The wedge is then excised using an oscillating saw, leaving at its apex intact medial cortex. The elbow is extended and the wedge closed by fracturing the medial cortex, carefully maintaining a periosteal hinge. With the forearm in supination, the carrying angle can be assessed clinically. If this is satisfactory, the cut surfaces are firmly opposed by tightening a wire loop around the heads of the two screws. If judged necessary from examination before operation, rotational deformity may be corrected at the same time by off-setting the distal screw anteriorly and the proximal screw posteriorly (Fig. 1), thus producing lateral rotation distally. The osteotomy is protected with a plaster of Paris back-splint (with the arm held at $90^{\circ}$ ) for three weeks, and active mobilisation is then gradually started.

\section{RESULTS}

Twenty-seven of the 32 cases were reviewed clinically by one of the authors (MCB). Follow-up after osteotomy was from 3 months to 7 years with a mean period of 41 months. Five patients were not available for review, but all had been seen from 3 to 7 months after operation. Radiographs taken shortly after osteotomy were available for all patients, and films were taken of the affected elbow in the 27 patients reviewed later. A lateral film and an anteroposterior film taken with the elbow extended and the forearm supinated were available.

Clinical assessment (Table II). As regards appearance there was an unsightly scar in four cases and a bulge on the lateral side of the arm at the level of the osteotomy in six. Both blemishes were less common after French's technique. 
Table II. Results of clinical assessment in 27 children before and after osteotomy for cubitus varus deformity

\begin{tabular}{|c|c|c|c|c|c|c|c|c|}
\hline \multirow[b]{3}{*}{ Case } & \multirow{2}{*}{\multicolumn{2}{|c|}{$\begin{array}{l}\text { *Carrying angle before } \\
\text { operation } \\
\text { (degrees) }\end{array}$}} & \multirow{3}{*}{$\begin{array}{l}\text { Fixation of } \\
\text { osteotomy }\end{array}$} & \multirow{3}{*}{$\begin{array}{l}\text { Follow-up } \\
\text { (months) }\end{array}$} & \multicolumn{4}{|c|}{ After operation } \\
\hline & & & & & \multirow{2}{*}{$\begin{array}{l}\text { *Carrying } \\
\text { angle } \\
\text { (degrees) }\end{array}$} & \multirow{2}{*}{$\begin{array}{l}\text { Difference in range } \\
\text { between affected and } \\
\text { normal elbow } \\
\text { (degrees) }\end{array}$} & \multirow[b]{2}{*}{ Complications } & \multirow[b]{2}{*}{ Results } \\
\hline & Normal & Affected & & & & & & \\
\hline 1 & +10 & -35 & French & 17 & +2 & +2 & Lateral bulge & Good \\
\hline 2 & +3 & -15 & French & 35 & +2 & 0 & Unsightly scar & Excellent \\
\hline 3 & +10 & Varus & French & 48 & +5 & -6 & None & Excellent \\
\hline 4 & +13 & Varus & French & 45 & +11 & -4 & None & Excellent \\
\hline 5 & +10 & -20 & French & 3 & 0 & -15 & None & Good \\
\hline 6 & +10 & Varus & French & 56 & +5 & -3 & Lateral bulge & Excellent \\
\hline 7 & +10 & Varus & French & 71 & +6 & -2 & None & Excellent \\
\hline 8 & +8 & Varus & French & 59 & +8 & +6 & None & Excellent \\
\hline 9 & +5 & -35 & $\mathrm{~K}$ wires & 29 & +6 & -25 & None & Poor \\
\hline 10 & +13 & -10 & $\mathrm{~K}$ wires & 38 & +10 & -18 & None & Good \\
\hline 11 & +12 & -30 & $\mathrm{~K}$ wires & 39 & +5 & -5 & None & Good \\
\hline 12 & +3 & -15 & $\mathrm{~K}$ wires & 7 & +8 & -12 & None & Good \\
\hline 13 & +10 & -25 & $\mathrm{~K}$ wires & 85 & -10 & -10 & $\begin{array}{l}\text { Loss of fixation, varus, } \\
\text { lateral bulge }\end{array}$ & Poor \\
\hline 14 & +8 & -12 & $\mathrm{~K}$ wires & 36 & +10 & +3 & $\begin{array}{l}\text { Pin-track infection, } \\
\text { unsightly scar }\end{array}$ & Excellent \\
\hline 15 & +7 & -15 & French & 14 & +7 & +2 & None & Excellent \\
\hline 16 & +7 & -15 & $\mathrm{~K}$ wires & 55 & +10 & +1 & $\begin{array}{l}\text { Pin-track infection, } \\
\text { unsightly scar }\end{array}$ & Excellent \\
\hline 17 & +10 & -15 & French & 33 & +12 & +5 & None & Excellent \\
\hline 18 & +15 & -10 & French & 47 & +17 & -7 & None & Excellent \\
\hline 19 & +10 & -20 & $\mathrm{~K}$ wires & 38 & -20 & -60 & $\begin{array}{l}\text { Pin-track infection, loss of } \\
\text { fixation, varus, lateral bulge }\end{array}$ & Poor \\
\hline 20 & +10 & Varus & Plaster & 48 & +5 & -3 & Lateral bulge & Excellent \\
\hline 21 & +10 & -10 & French & 26 & +3 & -20 & None & Good \\
\hline 22 & +10 & -15 & Piaster & 33 & +5 & -10 & $\begin{array}{l}\text { Loss of position, } \\
\text { remanipulation, lateral } \\
\text { bulge }\end{array}$ & Excellent \\
\hline 23 & +5 & Varus & $\mathrm{K}$ wires & 76 & +6 & -3 & Unsightly scar & Excellent \\
\hline 24 & +5 & -20 & French & 3 & +4 & -3 & None & Excellent \\
\hline 25 & +8 & -30 & $\mathrm{~K}$ wires & 31 & +4 & -5 & None & Excellent \\
\hline 26 & +7 & -15 & Plaster & 76 & -10 & -8 & Loss of position, varus & Poor \\
\hline 27 & +10 & -20 & $\mathrm{~K}$ wires & 56 & +8 & +2 & None & Excellent \\
\hline
\end{tabular}

*Carrying angle: + valgus; - varus

In 20 of the 27 patients the carrying angle differed from that of the normal side by $5^{\circ}$ or less. In three cases the difference was more than $10^{\circ}$ and some varus deformity remained. This was due to failure of fixation rather than failure to excise an adequate wedge. In two of these cases loss of fixation was due to pin-track infection and loosening of the Kirschner wires (Figs 2 to 5). In the third case no internal fixation had been used and a long-arm cast with the forearm pronated had failed to control the osteotomy
(Figs 6 to 8). Loss of correction also occurred in another patient managed by a long-arm cast ; in this case correction was regained by closed manipulation under anaesthesia and then maintained.

The range of movement in flexion and extension at the treated elbow was reduced by more than $20^{\circ}$ in only two cases. Significant loss of rotation or alteration of its arc at the shoulder was not seen.

The carrying angle and the range of elbow move- 


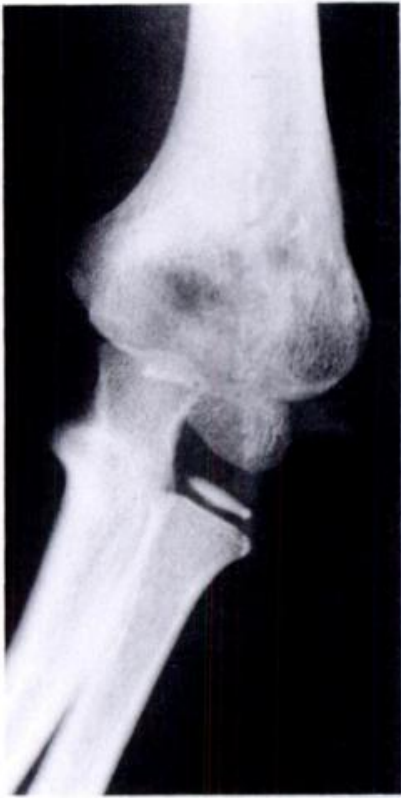

Fig. 2

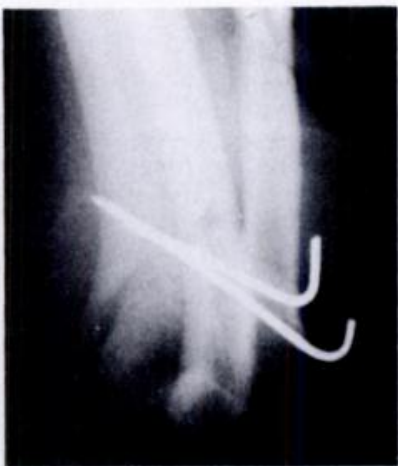

Fig. 3

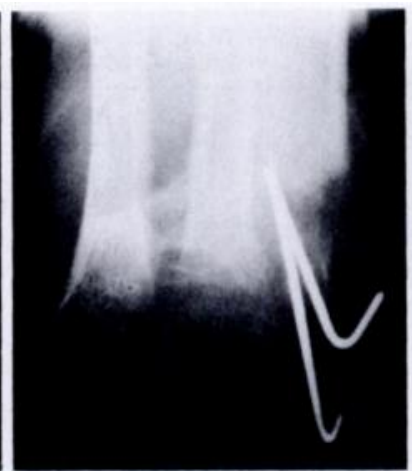

Fig. 4

Case 13. Figure 2 - Cubitus varus deformity 12 months after closed reduction of a left supracondylar fracture. Figure 3 Shortly after correction of the deformity by a lateral closing wedge osteotomy and fixation with two Kirschner wires. Figure 4 - Three weeks after operation there is loss of fixation and recurrence of deformity. Figure 5 - Cubitus varus deformity 26 months after osteotomy.

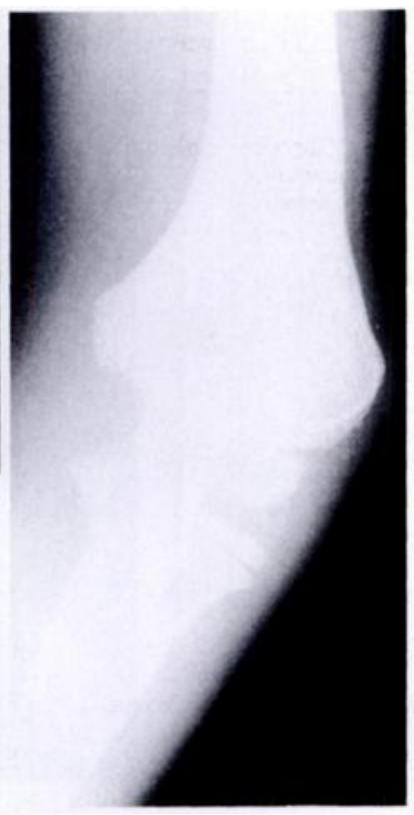

Fig. 5 ment, compared with the normal side, were combined to grade the results of the methods of treatment in this series. An excellent result was one with loss of carrying angle of $5^{\circ}$ or less, and loss of the range of flexion and extension by $10^{\circ}$ or less. A good result was one in which the loss of carrying angle was from $6^{\circ}$ to $10^{\circ}$, and the loss of flexion and extension was $20^{\circ}$ or less. A poor result was one in which the difference in carrying angle was over $10^{\circ}$ or the range of flexion and extension was limited by more than $20^{\circ}$.

Of the 16 patients in this series having a supracon-
Tabel III. Clinical results of 27 children after supracondylar osteotomy according to the method of fixation

\begin{tabular}{|lllll|}
\hline & \multicolumn{2}{l}{ Results } & \\
\cline { 2 - 4 } Method of holding & Excellent & Good & Poor & Total \\
\hline French's technique & 10 & 3 & 0 & 13 \\
Kirschner wires & 5 & 3 & 3 & 11 \\
Plaster cast & 2 & 0 & 1 & 3 \\
\hline
\end{tabular}

dylar osteotomy by the technique of French (1959), 13 were reviewed. Ten of these had an excellent result (Figs

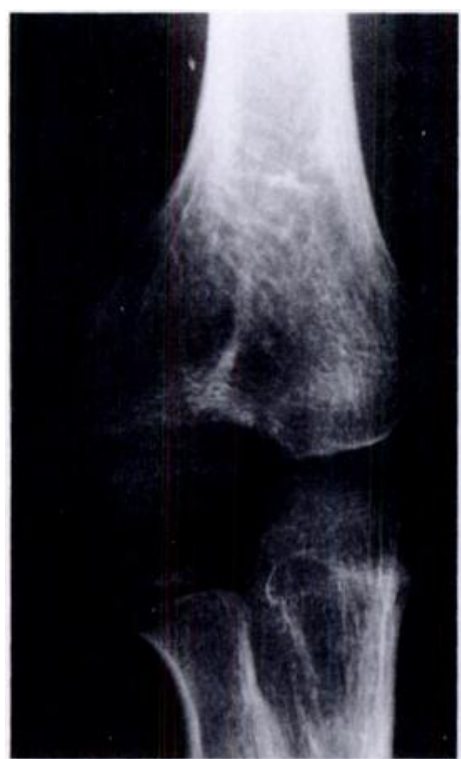

Fig. 6

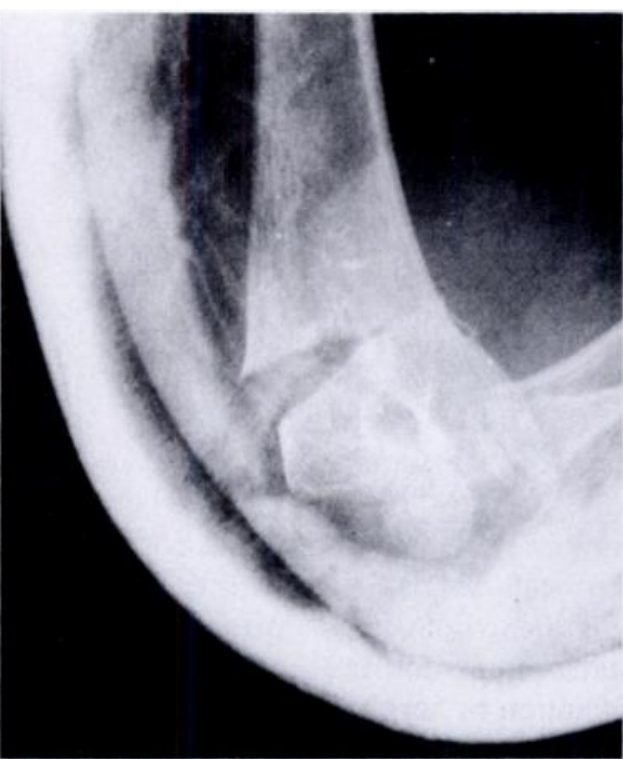

Fig. 7

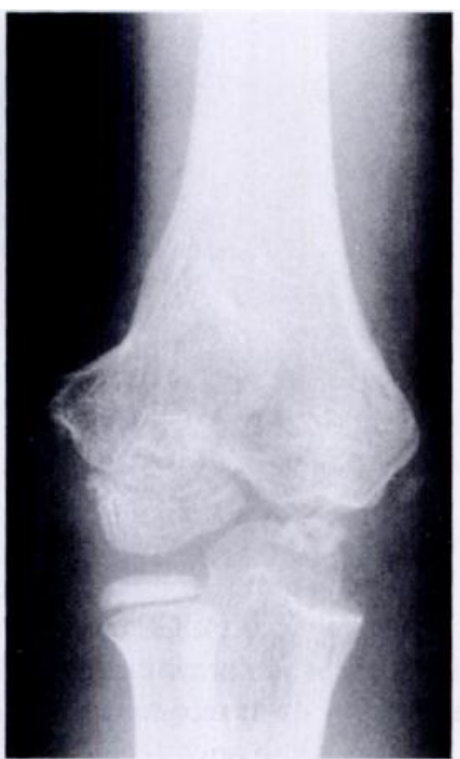

Fig. 8

Case 22. Figure 6-Cubitus varus deformity of the right elbow 30 months after treatment of a supracondylar fracture by open reduction and $\mathrm{Kirschner}$ wire fixation. Figure 7 - One week after a lateral closing wedge osteotomy with plaster cast fixation: there has been loss of correction. Figure 8-Thirty-three months after osteotomy and remanipulation there is incomplete correction of deformity. 


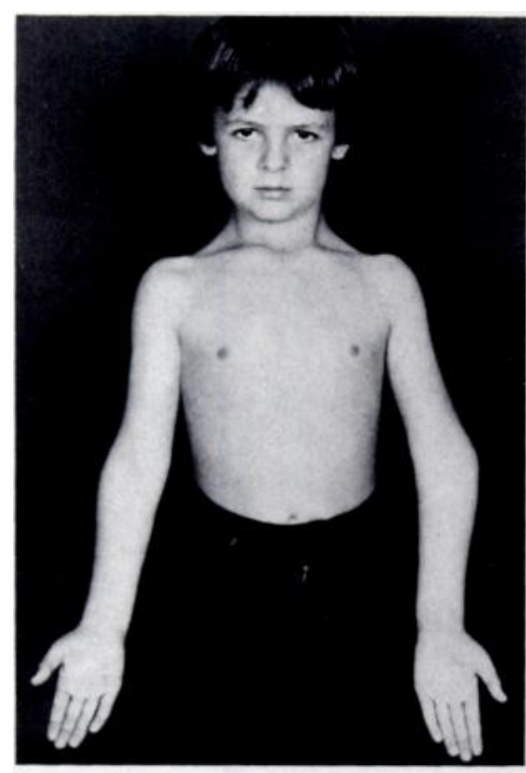

Fig. 9

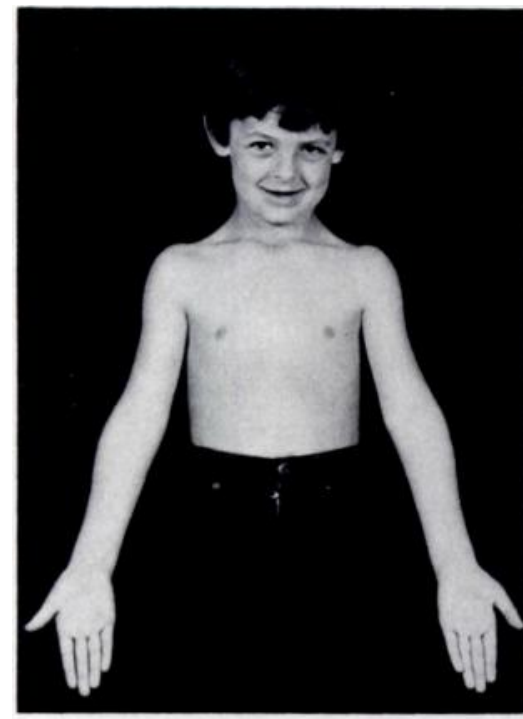

Fig. 11

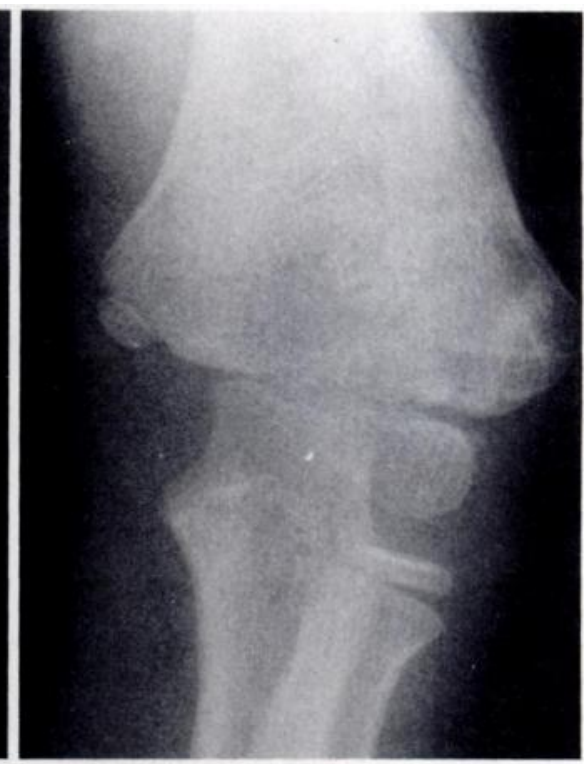

Fig. 10

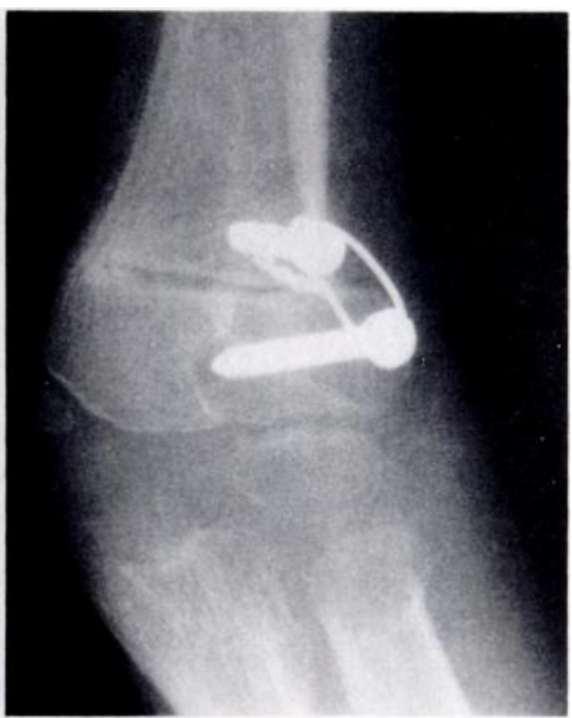

Fig. 12

Case 24. Figures 9 and 10-Cubitus varus deformity of the left elbow 34 months after treatment by closed reduction for a supracondylar fracture. Figures 11 and $12-$ Six weeks after French's osteotomy there is good correction of the deformity. Note the periosteal reaction on the medial side of the humerus.

9 to 12 ) and three had a good result. The Kirschner wire and plaster methods of holding were less satisfactory (Table III).

Radiographic assessment. No radiographic evidence was seen that growth disturbance had been a cause of cubitus varus deformity. Neither was there evidence of recurrence of varus deformity after osteotomy, in that the correction on early postoperative radiographs was unchanged on late review. Radiographs at review were not very helpful in assessing correction of varus since no control films were taken of the normal side. Loss of correction due to inadequate fixation was, however, evident on films taken soon after operation.

\section{DISCUSSION}

Outward angulation of the supinated forearm at the extended elbow, the "carrying angle", is present in utero and is completely developed in the newborn baby (King and Secor 1951). Under normal conditions it is unchanged throughout life and is not altered by secondary sexual development (Steel and Tomlinson 1958).

Smith, in 1960, studied 150 normal children and found the average carrying angle to be $6.1^{\circ}$ in girls and $5.4^{\circ}$ in boys. A change in the carrying angle after treatment of a supracondylar fracture may result from inadequate reduction, from loss of reduction with consequent malunion, or from disturbance of growth at 
the lower end of the humerus. Most authors consider that the deformity results from inadequate reduction, leaving a residual rotatory deformity which can collapse into medial or lateral tilt and therefore a varus or valgus deformity (Dunlop 1939; French 1959; Smith 1960; Amspacher and Messenbaugh 1964; Arnold, Nasca and Nelson 1977). The acceptance of inadequate reduction is partly due to the great difficulty of assessing the clinical carrying angle in the flexed elbow (Bosanquet and Middleton 1983). It is also difficult to obtain adequate anteroposterior radiographs when the elbow is in this position (Smith 1960).

There is little published support for growth disturbance as a cause of deformity after supracondylar fracture. No progression of deformity has been reported in the growing child; nor can the great preponderance of varus over valgus deformity be explained on this basis (Smith 1960; D’Ambrosia 1972).

Attenborough in 1953 reported four cases in which inadequate closed reduction led to deformity. In three of these varus angulation occurred and he postulated that "this may have been caused partly by disturbance of growth at the lower humeral epiphyseal line", but offered no supporting evidence. Siris, in 1939, analysed 330 supracondylar fractures and stated that "premature ossification of the epiphyses occurred in 12 cases producing loss of growth of part of the affected epiphysis. Normal growth on the unaffected side produced an abnormal carrying angle". However, in all these cases the fracture extended through the epiphysial cartilage plate and it is accepted that fractures involving the plate and the epiphyses may cause growth disturbance. By definition, a supracondylar fracture does not directly involve the epiphysial plate or the distal epiphyses, and Siris did not demonstrate growth disturbance in any true supracondylar fracture. Madsen (1955) reported two cases with disturbance of growth at the epiphysial line causing varus deformity and Høyer (1952) reported two cases in which impaired growth of the trochlea was accompanied by varus deformity.

In the present series there was no evidence of deformity due to growth disturbance, and in all cases there had been inadequate reduction. After union of the corrective osteotomy no deterioration in the carrying angle had occurred. As growth disturbance is so rarely significant there is no need to wait for cessation of growth before correcting the deformity, as was advised by Siris (1939). The ugliness of the elbow is most apparent when full elbow movement has returned after the fracture, and this is a good time to perform the osteotomy.

The significance of medial rotation deformity in malunited supracondylar fracture is debatable. This deformity does not affect mobility of the elbow but may limit apparent shoulder rotation (Ariño et al. 1977). Ariño et al. reported that spontaneous correction of any rotational deformity occurred during growth. Mitchell and Adams (1961) also found gradual regression of rotational deformity after a supracondylar fracture. Others have disputed the possibility of spontaneous correction of rotational deformity of the humerus (Attenborough 1953; French 1959; Amspacher and Messenbaugh 1964; El-Sharkawi and Fattah 1965).

In our series, patients treated by French's technique had any suspected medial rotation deformity corrected, in addition to correction of varus deformity by the lateral closing wedge. All other patients had a lateral closing wedge only. At late review the range and arc of shoulder rotation in the two groups was the same. It seems that any rotational component in cubitus varus deformity is of no consequence and that a lateral closing wedge will be adequate in most cases.

Three types of osteotomy have been described for correction of varus deformity of the elbow (Table I): a medial opening wedge with bone graft; rotation of an oblique osteotomy; and a lateral closing wedge. King and Secor (1951) reported 15 cases in which a supracondylar osteotomy was opened medially and held by a tibial bone graft. This method has the great disadvantage that it necessitates anterior transposition of the ulnar nerve. Amspacher and Messenbaugh (1964) reported four cases in which rotation of an oblique osteotomy corrected varus angulation and rotational deformity simultaneously. This method creates the difficulty of achieving a two-plane correction with a single cut, and means that rotation is needed to correct the varus even though rotational deformity may be minimal.

A lateral closing wedge is the simplest means of correction and some rotation can be added if required. Holding the correction can be difficult, and several methods have been described (Table I).

Fixation in a cast with the elbow flexed and the forearm pronated provides an unreliable hold on the distal fragment and significantly increases the risk of ischaemia. Three of our patients were treated by this method. In one the cast had to be split for early ischaemia, and in two patients remanipulation was required for loss of position in the cast. Rang (1974) reported that three of eight patients treated in this way required further correction.

Fixation with Kirschner wires may provide an adequate hold but is associated with complications. Eleven of the 13 children treated with Kirschner wire fixation were reviewed; there had been pin-track infections in four, and three had unsightly scars. Pin loosening, loss of fixation and recurrent deformity occurred in two of the four children with pin-track infection. Rang (1974) treated 20 patients with $\mathrm{K}$-wire fixation and reported quite serious complications: an aneurysm of the brachial artery, infection of bone, nerve palsies, skin loss and loss of fixation. Sweeney (1975) reported the results of 14 osteotomies in which crossed wires were used; five of these patients had residual varus deformity.

The French technique uses an intact periosteal hinge medially and two screws with a wire loop laterally to 
control the distal fragment. In our 16 patients there was no loss of fixation, and the 13 cases reviewed all had excellent or good correction of deformity. There were no infections or neurovascular complications. The technique described by French compares favourably with the other methods reported for the correction of cubitus varus deformity following supracondylar fracture of the humerus.

\section{REFERENCES}

Amspacher JC, Messenbaugh JF Jr. Supracondylar osteotomy of the humerus for correction of rotational and angular deformities of the elbow. South Med J 1964;57:846-50.

Ariifo VL, Lluch EE, Ramirez AM, Ferrer J, Rodriguez L, Baixauli F. Percutaneous fixation of supracondylar fractures of the humerus in children. J Bone Joint Surg [Am] 1977;59-A:914-6.

Arnold JA, Nasca RJ, Nelson CL. Supracondylar fractures of the humerus: the role of dynamic factors in prevention of deformity. $J$ Bone Joint Surg [ Am] 1977; 59-A:589-95.

Attenborough CG. Remodelling of the humerus after supracondylar fractures in childhood. J Bone Joint Surg [Br] 1953; 35-B:386-95.

Bosanquet JS, Middleton RW. The reduction of supracondylar fractures of the humerus in children treated by traction-in-extension: a review of 18 cases. Injury 1983;14:373-80.

D'Ambrosia RD. Supracondylar fractures of the humerus: prevention of cubitus varus. J Bone Joint Surg [ Am] 1972;54-A:60-6.

Dunlop J. Transcondylar fractures of the humerus in childhood. J Bone Joint Surg 1939;21: 59-73.

El-Sharkawi AH, Fattah HA. Treatment of displaced supracondylar fractures of the humerus in children in full extension and supination. $J$ Bone Joint Surg [Br] 1965;47-B:273-9.

French PR. Varus deformity of the elbow following supracondylar fractures of the humerus in children. Lancet 1959;ii:439-41.

Grifin PP. Supracondylar fractures of the humerus. Pediatr Clin North Am 1975;22:477-86.

Høyer A. Treatment of supracondylar fracture of the humerus by skeletal traction in an abduction splint. J Bone Joint Surg [Am] 1952;34-A: 623-37.

King D, Secor C. Bow elbow (cubitus varus). J Bone Joint Surg [ Am] 1951;33-A:572-6.

Langenskiöld A, Kivilaakso R. Varus and valgus deformity of the elbow following supracondylar fracture of the humerus. Acta Orthop Scand 1967;38:313-20.

Madsen E. Supracondylar fractures of the humerus in children. J Bone Joint Surg [Br] 1955;37-B:241-5.

Mitchell WJ, Adams JP. Supracondylar fractures of the humerus in children: a ten-year review. JAMA $1961 ; 175: 573-7$.

Nassar A. Correction of varus deformity following supracondylar fracture of the humerus. J Bone Joint Surg [ Br] 1974; 56-B:572-3.

Rang M. Children's fractures. Philadelphia: JB Lippincott Company, 1974.

Siris IE. Supracondylar fracture of the humerus: analysis of 330 cases. Surg Gynecol Obstet 1939;68:201-22.

Smith L. Deformity following supracondylar fractures of the humerus. J Bone Joint Surg [ Am] 1960;42-A:235-52.

Steel FLD, Tomlinson JDW. The "carrying angle" in man. J Anat 1958;92:315-7.

Sweeney JG. Osteotomy of the humerus for malunion of supracondylar fractures. J Bone Joint Surg [Br] 1975:57-B: 117. 